\title{
Determination of Plant Growth Regulators in Chinese Herbal Medicine: A Comparison of Liquid (QuEChERS) and Solid (MSPD) Extraction Methods
}

\author{
Bingjun Han, ${ }^{\oplus *, a}$ Bing Qian, ${ }^{a, b, c}$ Yan He ${ }^{a}$ and Lixu Peng ${ }^{a, b}$ \\ ${ }^{a}$ Hainan Provincial Key Laboratory of Quality and Safety for Tropical Fruits and Vegetables, \\ Analysis and Testing Center, Chinese Academy of Tropical Agricultural Sciences, \\ 571101 Haikou, Hainan, China \\ ${ }^{b}$ Environment and Plant Protection Institute, Chinese Academy of Tropical Agricultural Sciences, \\ 571101 Haikou, Hainan, China \\ ${ }^{c}$ College of Environment and Plant Protection, Hainan University, 570228 Haikou, Hainan, China
}

\begin{abstract}
This work aimed to compare the methods for the determination of twenty plant growth regulators (PGRs) from Chinese herbal medicines by applying liquid and solid extraction methods simultaneously. Quick, easy, cheap, effective, rugged and safe (QuEChERS) and matrix solidphase dispersion (MSPD) were chosen as the liquid and solid extraction methods, respectively. Due to the complex matrix of herbal medicine, carbon nanotubes were selected as the solutions/ sorbents for the extraction and purification. The extracts were analyzed by ultra-performance liquid chromatography-triple quadrupole-mass spectrometry (UPLC-MS/MS). Both methods resulted in good efficiency for the extraction and purification. The recoveries fell in the range of $71-117 \%$ with relative standard deviations (RSDs) less than 19\%. The limits of detection were in the range of 0.01 to $3 \mu \mathrm{g} \mathrm{kg}{ }^{-1}$ with the two methods. The standards were prepared using the matrix matched standards due to the considerable matrix effects of the herbal medicines. Compared to the liquid method, the solid method required a smaller amount of sample, which is critical for PGR analysis of rare valuable herbal medicines. The two methods were applied for the determination of the twenty PGRs in different Chinese herbal medicine successfully.
\end{abstract}

Keywords: plant growth regulator, QuEChERS, MSPD, Chinese herbal medicine

\section{Introduction}

Herbal medicines have been widely used since ancient times in many countries. ${ }^{1}$ In recent decades, more and more people have chosen herbal medicines for their mild healing effects and lower side effects. ${ }^{2,3}$ The demand for herbal plants has rapidly increased with the increasing interest in herbal medicine use in both academic and industrial fields. Consequently, plant growth regulators (PGRs), which profoundly influence plant cell growth, have been used widely to improve production of herbal medicines. PGRs are numerous and are both naturally occurring and have synthetic substances that regulate plant growth and death. ${ }^{4,5}$ Most PGRs are considered to have low toxicity but they have been the subject of health concerns as previous studies have shown that some PGRs inactivate antioxidant defense systems or have teratogenic effects in vitro. ${ }^{6-8}$ Therefore,

*e-mail: hanbjun@163.com the development of a rapid and sensitive method to identify and quantify the PGRs in herbal medicine samples is particularly important for the fields of psychophysiology and food safety. ${ }^{9,10}$

Unfortunately, accurate analysis of PGRs in herbal medicines is a challenging task. ${ }^{11}$ One of the main problems is that herbal plants often contain a large amount of proteins, pigments, sugars and tannins, which contribute to a complex matrix that must be considered in the analysis. ${ }^{12-14}$ Another complication is the wide range of PGR chemical properties contributing to difficulties in the effective extraction of all the PGR components from herbal medicines. ${ }^{15-17}$ Therefore, sample preparation is a crucial step that must not only ensure extraction efficiency of analytical procedures, but also effectively eliminate the matrix complexity.

Typically, there are two different kinds of extraction for rapid multi-component analysis using either liquid solutions or solid sorbents..$^{18}$ In recent years, the quick, easy, cheap, effective, rugged, and safe (QuEChERS) method using liquid 
solutions has been developed for many types of chemicals, including pesticides, ${ }^{19,20}$ polycyclic aromatic hydrocarbons ${ }^{21}$ in fruits, ${ }^{22}$ honey products, ${ }^{23}$ water and soil. ${ }^{24}$ Additionally, the method has been applied to successfully identify PGRs with the advantages of rapidity, simplicity, and a reduced number of steps. ${ }^{24-26}$ However, the QuEChERS method requires a rather large sample (about $10 \mathrm{~g}$ ) making it unsuitable for rare herbal medicines, such as Ganoderma lucidum and Cordyceps militaries. Consequently, a solid extraction method, matrix solid-phase dispersion (MSPD) ${ }^{27}$ has been developed to disperse small amount of samples using a selective solid-phase for the extraction of analytes from solid, semisolid, and viscous matrices, including food, ${ }^{28}$ plant, ${ }^{29}$ biological ${ }^{30}$ and environmental ${ }^{31}$ samples. The greatest advantage of MSPD over previous methods is the small amount of sample it requires for extraction, making it suitable for rare herbal medicines.

To our knowledge, there is few effective standardized extraction methods for analyzing PGRs in herbal medicines. ${ }^{32,33}$ QuEChERS and MSPD are two different extraction methods using liquid solvents and solid sorbents, respectively. Most importantly, the different sample amounts required by each extraction method provide applications for rare herbal sample analyses. The main objective of this work was to compare and choose a method with different extraction solvents/materials and sample amounts and attain the highest possible recoveries, good precision, and a low level of co-extracted matrix compounds. To determine recoveries and precision, two parallel herbal medicine samples were extracted using the above mentioned methods and subsequently analyzed with ultra-performance liquid chromatography-triple quadrupole-mass spectrometry (UPLC-MS/MS). ${ }^{34,35}$ The influence of the co-extractives on sensitivity was assessed by calculating matrix effects.

\section{Experimental}

\section{Reagents}

All chemicals used in this work were of at least analytical grade. High purity $18.2 \mathrm{M} \Omega \mathrm{cm}$ ultrapure water was produced by a Milli-Q water purification system (Millipore, USA). The chemical structures of the 20 PGRs studied in the present work are shown in Figure S1 (Supplementary Information (SI) section). The PGR standards were purchased from Dr Ehrenstorfer (Augsburg, Germany) and were stored at $-20{ }^{\circ} \mathrm{C}$. Individual analyte stock solutions (1000 $\left.\mathrm{mg} \mathrm{L}^{-1}\right)$ were prepared in methanol and were stored in amber screw-capped glass vials in the dark at $-20{ }^{\circ} \mathrm{C}$ less than six months. Acetonitrile (ACN), methanol, and formic acid (FA) (all high-performance liquid chromatography (HPLC) grade) were provided by Thermo Fisher Scientific Inc. (Geel, Belgium). Primary secondary amine sorbent (PSA) and magnesium sulfate $\left(\mathrm{MgSO}_{4}\right)$ for both the QuEChERS and MSPD methods were obtained from Supelco (Bellefonte, PA, USA). Commercial multi-wall carbon nanotubes (CNTs) (purity > $95 \mathrm{wt} . \%$; 10-20 o.d. $\times 10-30 \mu \mathrm{m}$ length) obtained from Chengdu Organic Chemicals Co. Ltd. (Chengdu, China) were used for the extraction without manipulation. The two whole plant samples of Ganoderma lucidum and Cordyceps militaries were purchased from a local market in Haikou, China. The four stem and leaf samples of Hibiscus rosa-sinensis, Codiaeum variegatum, Lagerstroemia indica and Psychotria rubra were collected from Hainan Medical University (Haikou, China). The samples were stored at $-20{ }^{\circ} \mathrm{C}$ until analysis, completed within 7 days.

\section{Sample preparation and extraction}

Liquid and solid methods that are in widespread use were evaluated for PGR testing in herbal medicines. A description of the extraction methods and a related procedure were included below.

\section{QuEChERS extraction}

A modified QuEChERS method was chosen for the sample preparation in the initial experiment. ${ }^{20}$ Briefly, a $10 \mathrm{~g}$ portion of milled sample was added to a $50 \mathrm{~mL}$ polytetrafluoroethylene (PTFE) centrifuge tube. Then, $20 \mathrm{~mL}$ of acetonitrile containing $1 \%$ formic acid (v/v) was added and the samples were homogenized for $2 \mathrm{~min}$. After that, $2 \mathrm{~g}$ of sodium chloride were added and the samples were vigorously shaken for $1 \mathrm{~min}$. The extract was then centrifuged (15000 rpm) for $5 \mathrm{~min}$. Afterwards, $5 \mathrm{~mL}$ of the supernatant (acetonitrile phase) was transferred to a $15 \mathrm{~mL}$ graduated centrifuge tube containing $100 \mathrm{mg}$ of CNTs and $500 \mathrm{mg}$ of $\mathrm{MgSO}_{4}$, that was then vigorously shaken again for $1 \mathrm{~min}$. The tube was then centrifuged again $(15000 \mathrm{rpm})$ for $5 \mathrm{~min}$. Finally, $2.0 \mathrm{~mL}$ of acetonitrile extracts were used to evaporate to dryness, and then $1.0 \mathrm{~mL}$ of acetonitrile was added to redissolve the PGR targets. The solution was filtered through a $0.22 \mu \mathrm{m}$ PTFE filter, and analyzed by UPLC-MS/MS.

\section{MSPD extraction}

The MSPD method was completed according to the off-line MSPD procedure which was reported in the earlier studies ${ }^{36}$ Briefly, $0.20 \mathrm{~g}$ sample, $200 \mathrm{mg}$ CNTs and $500 \mathrm{mg}$ of $\mathrm{MgSO}_{4}$ were weighed into an agate mortar at first and then ground for around $5 \mathrm{~min}$ using an agate pestle to obtain a homogeneous mixture. Secondly, this mixture was 
quantitatively transferred to a $2.0 \mathrm{~mL}$ PTFE centrifuge tube, to which $1.0 \mathrm{~mL}$ acetonitrile containing $1 \%$ formic acid $(\mathrm{v} / \mathrm{v})$ was added and the contents were blended. Then the separation of the mixture was achieved by centrifugation at $15000 \mathrm{rpm}$ for $5 \mathrm{~min}$. All the acetonitrile supernatant were transferred and evaporated to dryness. Finally, $0.2 \mathrm{~mL}$ of acetonitrile was added to dissolve the extracts and the liquid acetonitrile phase was filtered through a $0.22 \mu \mathrm{m}$ PTFE filter and subjected to UPLC-MS/MS analysis.

\section{Analytical procedure}

The effect of different sorbents on the extraction efficiency was firstly investigated in this work. $100 \mathrm{mg}$ of PSA, graphitized carbon black (GCB), C18, and CNTs were tested in the study for their influence on the QuEChERS and MSPD methods. For the low concentration of PGRs in herbal medicine, a spiked herbal sample with the concentration of PGR at $0.05 \mu \mathrm{g} \mathrm{g}^{-1}$ was used for the extraction.

To evaluate the linearity of the method, the standard solutions with different concentrations were analyzed. Linear regression curves were fitted to the integration area values corresponding to peaks as a function of the concentration of the standards. The limits of detection (LODs) and quantification (LOQs) were considered the lowest analytical concentrations that yielded a signal-to-noise ratio $(\mathrm{S} / \mathrm{N})$ of 3 and 10 , respectively. It must be noticed that both the liquid and solid methods had the same working dilution ratios and instrumental conditions, the analytical performances were the same for the two methods. Furthermore, recovery tests were performed at concentration levels of $0.05,0.1$ and $0.5 \mu \mathrm{g} \mathrm{g}^{-1}$. Matrix effects were assessed by comparing the slopes of five-point matrix-matched calibration curves with the slopes of calibration curves in the solvent. Matrix effects (ME) were calculated with the equation 1 .

$\operatorname{ME}(\%)=[($ slope in matrix / slope in solvent $)-1] \times 100$

The liquid and solid extraction methods were applied to the analysis of 20 PGRs in herbal medicine samples from different manufacturers or different batches. Acetonitrile was used as the solvents and the contents were calculated with external matrix standard methods based on the respective calibration curves.

\section{UPLC-MS/MS analysis}

\section{UPLC parameters}

MS detector could provide multi-channel signals for the different PGRs. Therefore, the UPLC condition mainly concerned about the short analytical time and good peak shape. Quantitative analysis was carried out on a Waters Acquity UPLC system (Waters, Corp., Milford, MA, USA) coupled to an API 4000 triple quadrupole MS (AB Sciex, Chromos, Singapore) equipped with an electrospray ionization source. According to the previous work, ${ }^{14} \mathrm{LC}$ separation was equipped with an Acquity UPLC BEH C18 column $(50 \times 2.1 \mathrm{~mm}, 1.7 \mu \mathrm{m})$ at $30{ }^{\circ} \mathrm{C}$. The typical gradient elution program was as follows: starting at $10 \%$ acetonitrile- $90 \%$ water (containing $0.1 \%$ formic acid), increasing acetonitrile to $90 \%$ in 5 min and keeping constant for $3 \mathrm{~min}$, then decreasing acetonitrile to $10 \%$ in $9 \mathrm{~min}$ and keeping constant for $1 \mathrm{~min}$. The flow rate was $0.25 \mathrm{~mL} \mathrm{~min}^{-1}$. The sample injection volume was $2 \mu \mathrm{L}$.

\section{MS/MS parameters}

MS detection was performed in the single reaction monitoring (SRM) mode using positive and negative ionization. The electrospray ionization (ESI) source settings were: temperature, $550{ }^{\circ} \mathrm{C}$; nebulizer gas, $50 \mathrm{psi}$; ion spray voltage, 5500 and $-4500 \mathrm{~V}$ for positive and negative modes, respectively. Nitrogen served as the nebulizer and collision gas. Qualitative and quantitative analyses software (AB Sciex $)^{37}$ was used for method development and data acquisition. In order to obtain the maximum sensitivity for identification and quantification of the PGR compounds, declustering potential (DP) and collision energy (CE) of MS parameters were carefully evaluated for each PGR using $1 \mu \mathrm{g} \mathrm{mL}^{-1}$ standard solution in methanol. The MS was operated in an SRM mode with a resolution set to unity for $\mathrm{Q} 1$ and $\mathrm{Q} 3$. The values of the optimized parameters and the selected SRM transitions in the analytical method are shown in Table 1. In order to get suitable identification and thus avoid overestimations or false positive findings, each compound required the acquirement of two SRM ions. The most intense SRM ion was selected for quantitation purposes (SRM1). Another ion was used for the qualitation (SRM2), when the retention time coincided with SRM1.

\section{Results and Discussion}

\section{Instrumental parameters}

To quantify the 20 PGRs constituents in herbal medicines, MS analysis was completed using electrospray ionization (ESI). Both positive (ESI+) and negative (ESI-) ion modes were investigated for each PGR to obtain higher response signals. Acquisition parameters of the mass spectrometer were optimized by direct continuous pump infusion of standard working solution of the PGRs 
Table 1. MS/MS parameters of the 20 PGRs

\begin{tabular}{|c|c|c|c|c|c|c|c|}
\hline Analyte & $\begin{array}{c}\text { Ionization } \\
\text { mode }\end{array}$ & $\begin{array}{l}\text { Parent ion } \\
(\mathrm{m} / \mathrm{z}) / \mathrm{amu}\end{array}$ & $\mathrm{DP} / \mathrm{V}$ & $\begin{array}{c}\text { Product ion } 1 \\
(\mathrm{~m} / \mathrm{z}) / \mathrm{amu}\end{array}$ & $\mathrm{CE} 1 / \mathrm{eV}$ & $\begin{array}{c}\text { Product ion } 2 \\
(\mathrm{~m} / \mathrm{z}) / \mathrm{amu}\end{array}$ & $\mathrm{CE} 2 / \mathrm{eV}$ \\
\hline Trinexapac-ethyl & ESI+ & 253.3 & 85.0 & 207.0 & 17.2 & 185.0 & 17.8 \\
\hline 6-BA & ESI+ & 225.7 & 80.0 & 91.0 & 29.5 & 147.9 & 25.2 \\
\hline Thidiazuron & ESI+ & 221.0 & 200.0 & 102.1 & 30.9 & 73.1 & 24.5 \\
\hline Chlormequat chloride & ESI+ & 122.3 & 81.2 & 58.1 & 35.9 & 63.1 & 29.6 \\
\hline Paclobutrazol & ESI+ & 294.1 & 70.0 & 70.2 & 41.5 & 125.1 & 46.8 \\
\hline Uniconazole & ESI+ & 292.3 & 107.1 & 70.0 & 41.8 & 125.0 & 41.7 \\
\hline Forchlorfenuron & ESI+ & 248.0 & 84.2 & 128.8 & 24.8 & 155.1 & 20.0 \\
\hline Mepiquat chloride & ESI+ & 114.1 & 75.0 & 98.1 & 35.9 & 58.2 & 35.9 \\
\hline Butralin & ESI+ & 296.2 & 54.0 & 148.8 & 27.0 & 240.1 & 19.0 \\
\hline TIBA & ESI- & 498.5 & -100.0 & 454.7 & -108.2 & 126.7 & -25.9 \\
\hline 2,4-D & ESI- & 218.7 & -126.1 & 160.8 & -17.1 & 125.2 & -35.9 \\
\hline 4-CPA & ESI- & 184.8 & -115.7 & 126.9 & -17.1 & 140.8 & -11.9 \\
\hline $\mathrm{GA}_{3}$ & ESI- & 345.1 & -127.3 & 238.9 & -18.9 & 142.9 & -35.6 \\
\hline Clopyralid & ESI- & 191.8 & -89.1 & 147.7 & -11.9 & 111.9 & -15.1 \\
\hline NAA & ESI- & 184.6 & -117.9 & 126.8 & -17.1 & 140.7 & -12.1 \\
\hline ABA & ESI- & 263.1 & -127.1 & 152.9 & -14.9 & 218.8 & -17.3 \\
\hline Daminozide & ESI- & 162.8 & -138.8 & 126.6 & -21.6 & 124.7 & -21.9 \\
\hline IAA & ESI- & 173.9 & -64.0 & 129.7 & -12.7 & 127.9 & -22.2 \\
\hline IBA & ESI- & 201.9 & -123.5 & 158.0 & -18.2 & 115.7 & -21.0 \\
\hline Chlorpropham & ESI- & 211.8 & -58.3 & 151.7 & -15.4 & 125.8 & -14.7 \\
\hline
\end{tabular}

MS/MS: triple quadrupole-mass spectrometry; PGRs: plant growth regulators; DP: declustering potential; CE: collision energy; ESI: electrospray ionization; 6-BA: 6-benzylaminopurine; TIBA: 2,3,5-triiodobenzoic acid; 2,4-D: 2,4-dichlorophenoxyacetic acid; 4-CPA: 4-chlorophenoxyacetic acid; GA 3 : gibberellin acid 3; NAA: 1-naphthylacetic acid; ABA: abscisic acid; IAA: indole-3-acetic acid; IBA: $1 H$-indole-3-butanoicacid.

$(0.5 \mu \mathrm{g} \mathrm{mL}-1)$ at a flow rate of $20 \mu \mathrm{L} \mathrm{min}{ }^{-1}$ in the mass spectrometer. The chemical structures of 20 analytes were characterized based on their quasi-molecular ions $[\mathrm{M}+\mathrm{H}]^{+}$ or $[\mathrm{M}-\mathrm{H}]^{-}$and fragment ions. Full scan spectra were acquired over the $\mathrm{m} / \mathrm{z}$ range of $50-550$ amu with a cycle time of $1.0 \mathrm{~s}$ and a step size of $0.1 \mathrm{amu}$ for identification of the precursor ions. The selected protonated molecular ions are shown in Table 1. The DP was optimized for achieving the highest signal response of $[\mathrm{M}+\mathrm{H}]^{+}$or $[\mathrm{M}-\mathrm{H}]^{-}$. Further identification of the most two abundant fragment ions (qualification ion and quantification ion) and selection of

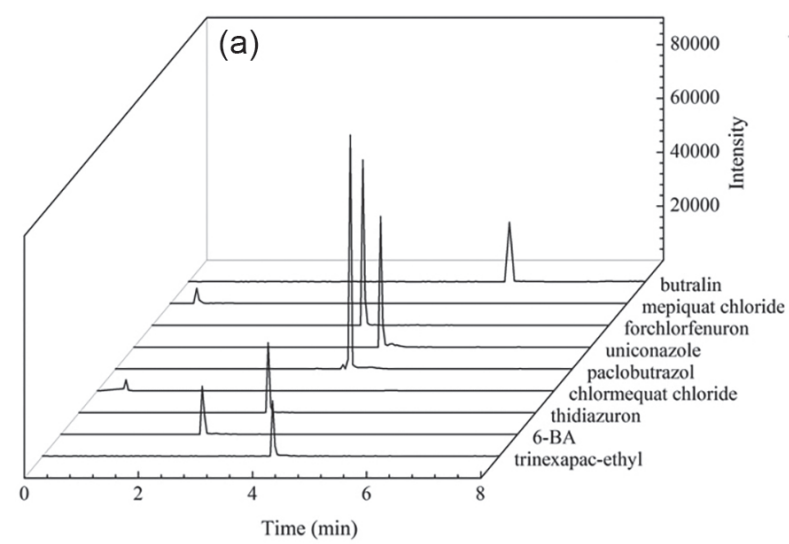

the optimum CE for PGRs was carried out in the product ion scan mode. The optimum MS conditions for each PGR are presented in Table 1, and the LC-MS/MS chromatograms of 20 PGRs compounds are shown in Figure 1.

\section{Comparison of extraction and purification}

The effects of different sorbents were the most important factor for the extraction and purification of PGR. The recoveries of 20 PGRs with the 4 different sorbents are summarized in Figure 2. PSA sorbent has been shown to

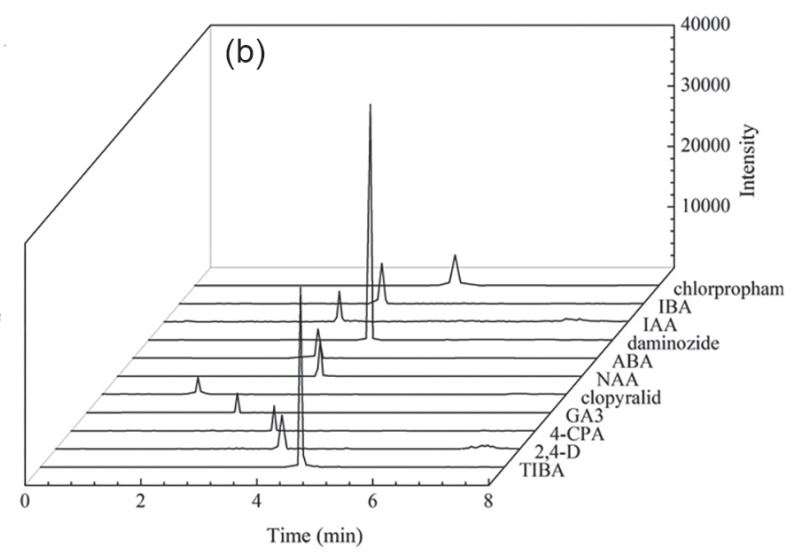

Figure 1. Typical LC-MS/MS chromatograms of 20 PGRs compounds. (a) ESI+ mode; (b) ESI- mode. 
be very useful for removal of larger amount of fatty acids and without a requirement for removal of pigments. ${ }^{20} \mathrm{In}$ our studies, the color of the eluate extracted with PSA was green, indicating that the pigment in the herbal plant could not be effectively removed by PSA sorbent. Moreover, the amine in PSA was strongly attracted to the polar PGRs with carboxylic acids. Therefore, the recoveries of most PGRs extracted and purified by PSA were below $40 \%$, indicating that the PSA was not suitable for the extraction of PGR.

GCB, C18 and CNTs were all carbon materials. GCB was used to remove pigments, and when treated, the green herbal plant extract became clear very quickly. However,
GCB could also have a negative effect on certain PGRs, especially those that could assume a planar shape like thidiazuron and trinexapac-ethyl. The extracted efficiencies of PGRs (mepiquat chloride, 2,4-dichlorophenoxyacetic acid (2,4-D), 4-chlorophenoxyacetic acid (4-CPA), gibberellin acid $3\left(\mathrm{GA}_{3}\right)$, clopyralid, 1-naphthylacetic acid (NAA), abscisic acid (ABA), daminozide, indole3-acetic acid (IAA), $1 H$-indole-3-butanoicacid (IBA), etc.) by the four materials were summarized in Figure 2 . Statistical significance was assessed by analysis of variance (ANOVA), followed by Tukey's post-hoc test, showed significant differences at the 0.05 level. The recoveries of
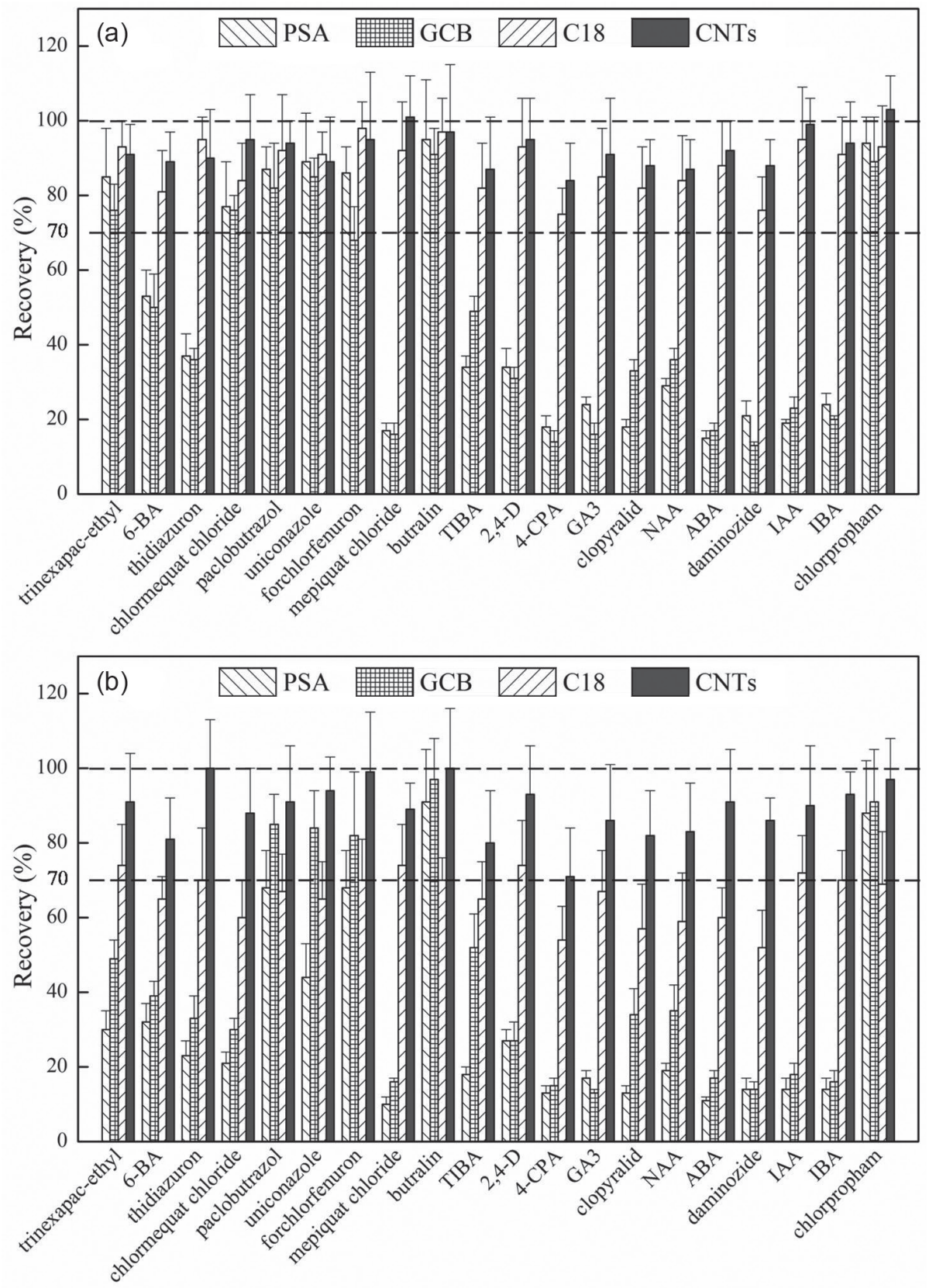

Figure 2. Comparison of extracted efficiency with different sorbents for liquid/solid extraction. (a) Liquid QuEChERS method; (b) solid MSPD method. 
PGRs were between 13 to $91 \%$ with liquid extraction and 14 to $97 \%$ with solid extraction. On the other hand, both C18 and CNTs provided high recoveries (75-103\%) for PGRs with liquid extraction. However, the satisfactory recoveries (71-101\%) could be obtained for the liquid extraction with CNTs, but the lowest recoveries occurred in the case of $\mathrm{C} 18$ for some PGRs like 4-CPA and clopyralid. The probable reason is the different hydrophobic characteristics for the reversed-phase sorbents. For C18 and PGRs, the strong hydrophobic interaction might cause strong adsorption of PGRs on the sorbent and difficulty in elution with solid extraction, leading to low recoveries. Therefore, CNTs was chosen as the sorbent for PGRs in herbal medicines for both the liquid and solid extraction and purification. Furthermore, the morphology of CNTs was tested before and after the ground step by scanning electron microscopy (SEM), and the results were presented in Figure 3. The ground step did not show any damage and morphological changes such as length shortening and desctruction of cylindrical nanostructure, which meant that the CNTs did not change its properties for the future extraction.

The effects of other experimental conditions for QuEChERS and MSPD method were investigated using $0.05 \mu \mathrm{g} \mathrm{mL}^{-1}$ of 4 PGR compounds as test analytes, and the results were shown in SI section in Figure S2. ACN volume of $10 \mathrm{~mL}$ and CNTs mass of $100 \mathrm{mg}$ were selected for QuEChERS method. CNTs mass of $200 \mathrm{mg}$ and grinding time of $5 \mathrm{~min}$ were chosen for MSPD extraction.

\section{Comparison of analytical performance}

The method quality parameters of the liquid and solid extraction method, including matrix effects, linearity, LOD and LOQ, repeatability and recovery were investigated to verify the suitability and performance for the determination of PGRs in herbal medicine, and the results were summarized in Table 2. The results of both the liquid and solid methods indicated good linearity $(\mathrm{R}>0.99)$ between investigated concentrations of 20 PGR compounds and their peak areas within the test ranges. The determined LODs were in the range of 0.01 to $3 \mu \mathrm{g} \mathrm{kg}^{-1}$, and LOQs were in the range of 0.05 to $10 \mu \mathrm{g} \mathrm{kg}^{-1}$.

Both the liquid and solid methods performed similar ME to the detected PGRs. As shown in Table 3, all the PGRs got matrix effects, which should not be ignored. Therefore, all the standards in the study should be prepared in matrix solution.

The recovery values at concentration level of 0.05 , 0.1 and $0.5 \mu \mathrm{g} \mathrm{g}^{-1}$ were calculated by comparison of PGR responses obtained from the herbal medicines using the liquid and solid extraction and purification, respectively. The overall recoveries of the 20 PGRs fell in the range of 78-117\% with QuEChERS method and 71-117\% with MSPD method. The relative standard deviations (RSDs) were less than $19 \%$, which met the requirement (20\% of RSD) at the concentration between 0.01 and $0.1 \mathrm{mg} \mathrm{kg}^{-1}$ in Chinese standard, ${ }^{38}$ indicating that both methods were accurate for the determination of PGRs in herbal medicines.

\section{Samples analysis}

The analytical results of real samples are summarized in Table 4, where ABA was found in four herbal plants and IAA was found in Hibiscus rosa-sinensis. The $t$-test showed that all the analytical results of PGRs found in the six
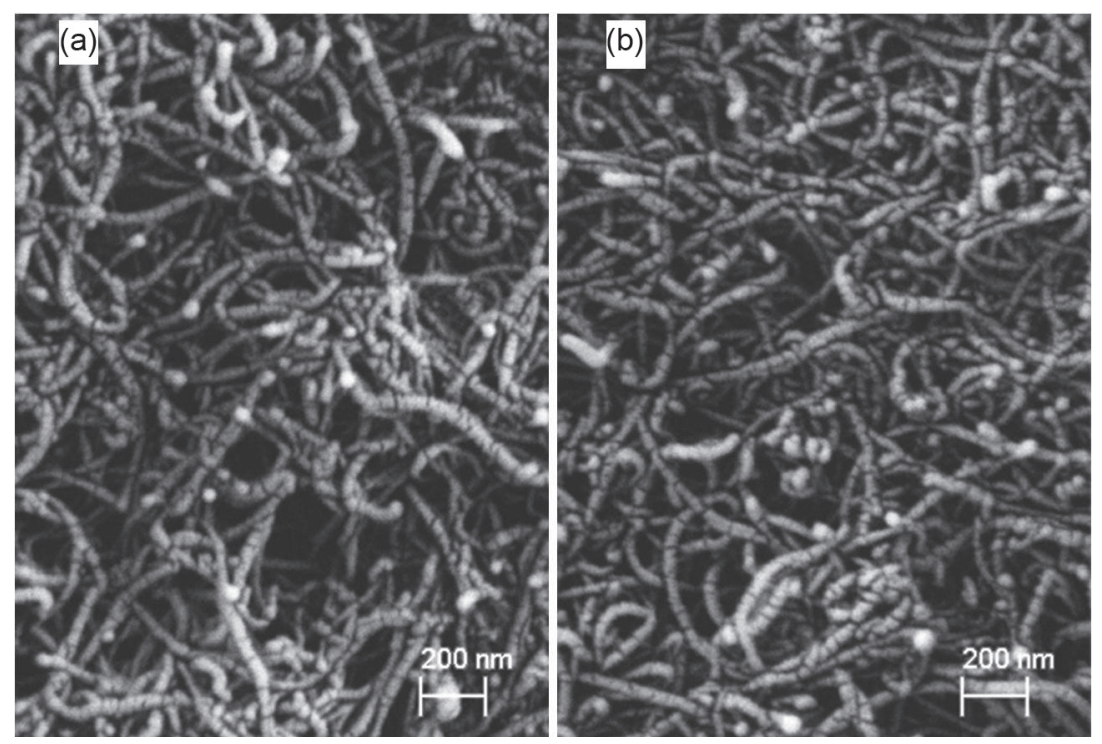

Figure 3. SEM images of CNTs: (a) before grind; (b) after grind. 
Table 2. Retention times $\left(\mathrm{t}_{\mathrm{R}}\right)$, linear relationship, LODs and LOQs of the 20 PGRs

\begin{tabular}{|c|c|c|c|c|c|c|}
\hline Analyte & $\mathrm{t}_{\mathrm{R}} / \min$ & $\begin{array}{c}\text { Linear range / } \\
\left(\mu \mathrm{g} \mathrm{L}^{-1}\right)\end{array}$ & Linear equation & $\mathrm{R}$ & $\mathrm{LOD} /\left(\mu \mathrm{g} \mathrm{kg}^{-1}\right)$ & $\mathrm{LOQ} /\left(\mu \mathrm{g} \mathrm{kg}^{-1}\right)$ \\
\hline Trinexapac-ethyl & 4.04 & $1-1000$ & $y=1.49 \times 10^{6} x+1.61 \times 10^{4}$ & 0.9995 & 0.2 & 1 \\
\hline 6-BA & 2.48 & $1-1000$ & $y=1.77 \times 10^{6} x+1.72 \times 10^{4}$ & 0.9999 & 0.2 & 1 \\
\hline Thidiazuron & 3.32 & $0.5-500$ & $y=3.04 \times 10^{5} x+1.55 \times 10^{4}$ & 0.9990 & 0.1 & 0.5 \\
\hline Chlormequat chloride & 0.50 & $10-1000$ & $y=6.83 \times 10^{4} x+849$ & 0.9989 & 3 & 10 \\
\hline Paclobutrazol & 4.12 & $0.05-500$ & $y=3.84 \times 10^{6} x+2.90 \times 10^{5}$ & 0.9986 & 0.01 & 0.05 \\
\hline Uniconazole & 4.36 & $0.2-500$ & $y=3.08 \times 10^{6} x+1.38 \times 10^{5}$ & 0.9996 & 0.06 & 0.2 \\
\hline Forchlorfenuron & 3.71 & $0.1-500$ & $y=4.86 \times 10^{6} x+2.04 \times 10^{5}$ & 0.9996 & 0.03 & 0.1 \\
\hline Mepiquat chloride & 0.59 & $5-1000$ & $y=5.36 \times 10^{5} x+4.35 \times 10^{3}$ & 0.9987 & 1 & 5 \\
\hline Butralin & 5.64 & $0.5-500$ & $y=1.21 \times 10^{6} x+4.92 \times 10^{3}$ & 0.9993 & 0.1 & 0.5 \\
\hline TIBA & 4.49 & $2-1000$ & $y=7.47 \times 10^{5} x+1.38 \times 10^{4}$ & 0.9993 & 0.6 & 2 \\
\hline $2,4-\mathrm{D}$ & 3.83 & $5-1000$ & $y=9.91 \times 10^{4} x-2.03 \times 10^{3}$ & 0.9986 & 1 & 5 \\
\hline 4-CPA & 3.50 & $5-1000$ & $y=7.47 \times 10^{5} x+1.38 \times 10^{4}$ & 0.9997 & 1 & 5 \\
\hline $\mathrm{GA}_{3}$ & 2.59 & $10-1000$ & $y=1.51 \times 10^{5} x+469$ & 0.9998 & 3 & 10 \\
\hline Clopyralid & 1.69 & $5-1000$ & $y=2.38 \times 10^{4} x+1.02 \times 10^{3}$ & 0.9994 & 1 & 5 \\
\hline NAA & 3.49 & $5-1000$ & $y=3.80 \times 10^{5} x-9.87 \times 10^{3}$ & 0.9990 & 1 & 5 \\
\hline $\mathrm{ABA}$ & 3.13 & $5-1000$ & $y=3.37 \times 10^{5} x-1.10 \times 10^{4}$ & 0.9998 & 1 & 5 \\
\hline Daminozide & 3.83 & $1-1000$ & $y=3.41 \times 10^{4} x-449$ & 0.9992 & 0.05 & 1 \\
\hline IAA & 2.97 & $10-1000$ & $y=1.01 \times 10^{6} x+2.20 \times 10^{4}$ & 0.9989 & 3 & 10 \\
\hline IBA & 3.50 & $10-1000$ & $y=1.20 \times 10^{5} x-4.00 \times 10^{3}$ & 0.9995 & 3 & 10 \\
\hline Chlorpropham & 4.49 & $10-1000$ & $y=5.02 \times 10^{4} x-2.42 \times 10^{3}$ & 0.9990 & 3 & 10 \\
\hline
\end{tabular}

R: correlation coefficient; LOD: limit of detection; LOQ: limit of quantification; 6-BA: 6-benzylaminopurine; TIBA: 2,3,5-triiodobenzoic acid; 2,4-D: 2,4-dichlorophenoxyacetic acid; 4-CPA: 4-chlorophenoxyacetic acid; GA : gibberellin acid 3; NAA: 1-naphthylacetic acid; ABA: abscisic acid; IAA: indole-3-acetic acid; IBA: $1 H$-indole-3-butanoicacid.

Table 3. Comparison of recoveries and matrix effects for the 20 PGRs between QuEChERS and MSPD method

\begin{tabular}{|c|c|c|c|c|c|c|c|c|}
\hline \multirow{3}{*}{ Analyte } & \multicolumn{6}{|c|}{ Recoveries $(\mathrm{n}=5) / \%$} & \multirow{2}{*}{\multicolumn{2}{|c|}{ Matrix effect }} \\
\hline & \multicolumn{3}{|c|}{ QuEChERS / $\left(\mu \mathrm{g} \mathrm{g}^{-1}\right)$} & \multicolumn{3}{|c|}{$\operatorname{MSPD} /\left(\mu \mathrm{g} \mathrm{g}^{-1}\right)$} & & \\
\hline & 0.05 & 0.10 & 0.50 & 0.05 & 0.10 & 0.50 & QuEChERS / \% & MSPD / \% \\
\hline Trinexapac-ethyl & 92 & 93 & 103 & 95 & 84 & 83 & 13.72 & 16.75 \\
\hline 6-BA & 91 & 84 & 103 & 82 & 93 & 99 & 12.71 & 14.51 \\
\hline Thidiazuron & 87 & 80 & 96 & 116 & 90 & 85 & -74.46 & -79.13 \\
\hline Chlormequat chloride & 117 & 92 & 90 & 89 & 82 & 88 & -36.27 & -40.06 \\
\hline Paclobutrazol & 94 & 87 & 101 & 90 & 83 & 108 & -11.53 & -10.81 \\
\hline Uniconazole & 83 & 104 & 108 & 91 & 99 & 110 & 14.78 & 11.67 \\
\hline Forchlorfenuron & 101 & 101 & 92 & 71 & 96 & 90 & 12.49 & 10.42 \\
\hline Mepiquat chloride & 98 & 92 & 101 & 95 & 98 & 102 & 10.08 & 11.49 \\
\hline Butralin & 98 & 93 & 81 & 104 & 80 & 100 & 34.19 & 27.46 \\
\hline Tiba & 81 & 108 & 101 & 81 & 106 & 102 & -31.88 & -35.73 \\
\hline $2,4-\mathrm{D}$ & 113 & 108 & 90 & 94 & 107 & 86 & 63.71 & 65.16 \\
\hline 4-CPA & 87 & 95 & 97 & 76 & 91 & 112 & -42.89 & -51.27 \\
\hline $\mathrm{GA}_{3}$ & 88 & 103 & 107 & 93 & 112 & 100 & -63.39 & -65.14 \\
\hline Clopyralid & 86 & 82 & 97 & 77 & 92 & 103 & 29.55 & 32.41 \\
\hline NAA & 92 & 108 & 81 & 80 & 86 & 86 & -43.91 & -47.67 \\
\hline $\mathrm{ABA}$ & 95 & 85 & 100 & 113 & 97 & 91 & -17.17 & -14.96 \\
\hline Daminozide & 87 & 89 & 102 & 84 & 87 & 87 & -24.78 & -23.16 \\
\hline IAA & 78 & 86 & 103 & 91 & 107 & 88 & 12.26 & 14.71 \\
\hline IBA & 90 & 88 & 85 & 90 & 97 & 107 & 13.82 & 12.06 \\
\hline Chlorpropham & 110 & 94 & 97 & 92 & 94 & 98 & -5.31 & -7.73 \\
\hline
\end{tabular}

QuEChERS: quick, easy, cheap, effective, rugged and safe; MSPD: matrix solid-phase dispersion; 6-BA: 6-benzylaminopurine; TIBA: 2,3,5-triiodobenzoic acid; 2,4-D: 2,4-dichlorophenoxyacetic acid; 4-CPA: 4-chlorophenoxyacetic acid; GA 3 : gibberellin acid 3; NAA: 1-naphthylacetic acid; ABA: abscisic acid; IAA: indole-3-acetic acid; IBA: $1 H$-indole-3-butanoicacid. 
Table 4. Comparison of the analytical results ${ }^{\mathrm{a}}$ of herbal medicine samples obtained by QuEChERS and MSPD (in parentheses)

\begin{tabular}{lcccccc}
\hline Analyte & $\begin{array}{c}\text { Ganoderma } \\
\text { lucidum }\end{array}$ & $\begin{array}{c}\text { Cordyceps } \\
\text { militaries }\end{array}$ & $\begin{array}{c}\text { Hibiscus } \\
\text { rosa-sinensis }\end{array}$ & $\begin{array}{c}\text { Codiaeum } \\
\text { variegatum }\end{array}$ & $\begin{array}{c}\text { Lagerstroemia } \\
\text { indica }\end{array}$ & $\begin{array}{c}\text { Psychotria } \\
\text { rubra }\end{array}$ \\
\hline ABA / $\left(\mathrm{mg} \mathrm{kg}^{-1}\right)$ & N.D. (N.D.) & N.D. (N.D.) & $\begin{array}{c}0.0720 \pm 0.009 \\
(0.0746 \pm 0.002)\end{array}$ & $\begin{array}{c}0.0768 \pm 0.003 \\
(0.071 \pm 0.011)\end{array}$ & $\begin{array}{c}0.0736 \pm 0.008 \\
(0.0706 \pm 0.005)\end{array}$ & $\begin{array}{c}0.0680 \pm 0.004 \\
(0.0702 \pm 0.012)\end{array}$ \\
\hline IAA / $\left(\mathrm{mg} \mathrm{kg}^{-1}\right)$ & N.D. (N.D.) & N.D. (N.D.) & $\begin{array}{c}0.0765 \pm 0.009 \\
(0.0712 \pm 0.013)\end{array}$ & N.D. (N.D.) & N.D. (N.D.) & N.D. (N.D.) \\
\hline
\end{tabular}

${ }^{a}$ Average \pm standard deviation of three trials. N.D.: not detectable; ABA: abscisic acid; IAA: indole-3-acetic acid.

herbal medicines by the two methods were no significantly different at the confidence level of $95 \%$.

\section{Conclusions}

In conclusion, both liquid QuEChERS and solid MSPD methods showed good efficiency for the extraction and purification of the PGRs in herbal medicine in view of the presented results. The UPLC-MS/MS determined and identified the PGR contents rapidly and sensitively. The overall recoveries of the 20 PGRs fell in the range of $71-117 \%$, with RSDs less than $19 \%$. The matrix effects of the herbal medicines were considerable which meant all the standards in the study had to be prepared using the matrix solution. Compared to the liquid method, the solid method required a small amount of sample, which is critical for PGR analysis of rare valuable herbal medicines.

\section{Supplementary Information}

Supplementary information, containing chemical structures of PGRs and effects of experimental conditions in this work, is available free of charge at http://jbcs.sbq.org.br as PDF file.

\section{Acknowledgments}

This project was funded in part by the National Science and Technology Major Project of the Ministry of Science and Technology of China (No. 16YFD0201203), the earmarked fund for China Agriculture Research System (No. CARS-31) and the Central Public-interest Scientific Institution Basal Research Fund for Chinese Academy of Tropical Agricultural Sciences (No. 1630082017005, 1630082019001).

\section{References}

1. Chan, T. Y. K.; Chan, J. C. N.; Tomlinson, B.; Critchley, J.; Lancet 1993, 342, 1532.

2. Zhu, Y. Z.; Huang, S. H.; Tan, B. K. H.; Sun, J.; Whiteman, M.; Zhu, Y. C.; Nat. Prod. Rep. 2004, 21, 478.
3. Calixto, J. B.; Braz. J. Med. Biol. Res. 2000, 33, 179.

4. Dobbelaere, S.; Vanderleyden, J.; Okon, Y.; Crit. Rev. Plant Sci. 2003, 22, 107.

5. Jiménez, M. V.; Plant Growth Regul. 2005, 47, 91.

6. Celik, I.; Tuluce, Y.; Isik, I.; J. Biochem. Mol. Toxicol. 2006, 20, 174.

7. Tuluce, Y.; Celik, I.; Pestic. Biochem. Physiol. 2006, 86, 85.

8. Barbosa, L. C. A.; Demuner, A. J.; Borges, E. E. L.; Mann, J.; J. Braz. Chem. Soc. 1997, 8, 19.

9. Zhang, H.; Tan, S. N.; Teo, C. H.; Yew, Y. R.; Ge, L.; Chen, X.; Yong, J. W. H.; Talanta 2015, 139, 189.

10. Wu, T.; Liang, Y.; Zhu, X.; Zhao, M.; Liu, H.; Anal. Bioanal. Chem. 2014, 406, 3239.

11. Liu, L.; Xia, L.; Wu, C.; Qu, F.; Li, G.; Sun, Z.; You, J.; Talanta 2016, 154, 23.

12. Cheng, X.-L.; Qi, L.-W.; Wang, Q.; Liu, X.-G.; Boubertakh, B.; Wan, J.-Y.; Liu, E. H.; Li, P.; Analyst 2013, 138, 2279.

13. Xie, S.; Wang, F.; Chen, Z.; Analyst 2013, 138, 1226.

14. Huang, H.; Zhang, J.; Xu, D.; Zhou, Y.; Luo, J.; Li, M.; Chen, S.; Wang, L.; Se Pu. 2014, 32, 707.

15. Cho, S.-K.; Abd El-Aty, A. M.; Park, K. H.; Park, J.-H.; Assayed, M. E.; Jeong, Y.-M.; Park, Y.-S.; Shim, J.-H.; Food Chem. 2013, 136, 1414.

16. Liu, M.; Chen, G.; Guo, H.; Fan, B.; Liu, J.; Fu, Q.; Li, X.; Lu, X.; Zhao, X.; Li, G.; Sun, Z.; Xia, L.; Zhu, S.; Yang, D.; Cao, Z.; Wang, H.; Suo, Y.; You, J.; J. Agric. Food Chem. 2015, 63, 8058.

17. Prasad, K.; Das, A. K.; Oza, M. D.; Brahmbhatt, H.; Siddhanta, A. K.; Meena, R.; Eswaran, K.; Rajyaguru, M. R.; Ghosh, P. K.; J. Agric. Food Chem. 2010, 58, 4594.

18. Fernandes, A. R.; de Souza, P. S.; de Oliveira, A. E.; Chaves, A. R.; J. Braz. Chem. Soc. 2018, 29, 695.

19. Anastassiades, M.; Lehotay, S. J.; Stajnbaher, D.; Schenck, F. J.; J. AOAC Int. 2003, 86, 412.

20. Rajski, L.; Lozano, A.; Belmonte-Valles, N.; Ucles, A.; Ucles, S.; Mezcua, M.; Fernandez-Alba, A. R.; Analyst 2013, 138, 921.

21. Smoker, M.; Tran, K.; Smith, R. E.; J. Agric. Food Chem. 2010 , $58,12101$.

22. Li, G.; Liu, S.; Sun, Z.; Xia, L.; Chen, G.; You, J.; Food Chem. 2015, 170, 123.

23. Albero, B.; Sánchez-Brunete, C.; Tadeo, J. L.; J. AOAC Int. 2003, 86, 576. 
24. Shuying, L.; Yihu, W.; Qianqian, S.; Wenjun, G.; Guonian, Z.; J. Sep. Sci. 2015, 38, 1900.

25. Shi, X.; Jin, F.; Huang, Y.; Du, X.; Li, C.; Wang, M.; Shao, H.; Jin, M.; Wang, J.; J. Agric. Food Chem. 2012, 60, 60.

26. Kim, K.-g.; Park, D.-w.; Kang, G.-r.; Kim, T.-s.; Yang, Y.; Moon, S.-j.; Choi, E.-a.; Ha, D.-r.; Kim, E.-s.; Cho, B.-s.; Food Chem. 2016, 208, 239.

27. Kristenson, E. M.; Brinkman, U. A. T.; Ramos, L.; TrAC, Trends Anal. Chem. 2006, 25, 96.

28. Wang, L.; Duan, C.; Wu, D.; Guan, Y.; J. Chromatogr. A 2014, $1359,44$.

29. Lu, Q.; Wu, J.-H.; Yu, Q.-W.; Feng, Y.-Q.; J. Chromatogr. A 2014, 1367, 39.

30. Li, D.; Yang, Q. L.; Wang, Z. M.; Su, R.; Xu, X.; Zhang, H. Q.; J. Sep. Sci. 2011, 34, 822.

31. Campíns-Falcó, P.; Verdú-Andrés, J.; Sevillano-Cabeza, A.; Molins-Legua, C.; Herráez-Hernández, R.; J. Chromatogr. A 2008, 1211, 13.
32. Meyer, A.; Miersch, O.; Büttner, C.; Dathe, W.; Sembdner, G.; J. Plant Growth Regul. 1984, 3, 1.

33. Mou, Y.-L.; Guo, D.-H.; Ding, Z.-P.; Yi, X.-H.; Quarantine, B.; Chin. J. Anal. Chem. 2013, 41, 1640.

34. Nordström, A.; Tarkowski, P.; Tarkowska, D.; Dolezal, K.; Åstot, C.; Sandberg, G.; Moritz, T.; Anal. Chem. 2004, 76, 2869.

35. Yi, T.; Leung, K. S. Y.; Lu, G.-H.; Zhang, H.; Chan, K.; Phytochem. Anal. 2007, 18, 181.

36. Deng, D. Y.; Zhang, S.; Chen, H.; Yang, L.; Yin, H.; Hou, X. D.; Zheng, C. B.; J. Anal. At. Spectrom. 2015, 30, 882.

37. Analyst 1.6.2, available at https://sciex.com/products/software/ analyst-software\#accordion2, accessed on January 12, 2019.

38. Chinese Standard NY/T 788-2018: Test Guidelines for Pesticide Residues in Crops; Ministry of Agriculture and Rural Affairs of the People's Republic of China, 2018.

Submitted: November 14, 2018

Published online: February 28, 2019 